\title{
Botany
}

\section{Measurement of inbreeding depression in Rhododendron kaempferi: seed production, germination, juvenile survival, and growth}

\begin{tabular}{|r|l|}
\hline Journal: & Botany \\
\hline Manuscript ID & cjb-2021-0038.R1 \\
\hline Manuscript Type: & Article \\
\hline Date Submitted by the \\
Author: & 18-Sep-2021 \\
\hline Complete List of Authors: & $\begin{array}{l}\text { Takahashi, Keigo; Shinshu University } \\
\text { Itino, Takao; Shinshu University }\end{array}$ \\
\hline Keyword: & bumblebee, germination, inbreeding depression, rhododendron, seed \\
\hline $\begin{array}{r}\text { Is the invited manuscript for } \\
\text { consideration in a Special } \\
\text { Issue? : }\end{array}$ & Not applicable (regular submission) \\
\hline &
\end{tabular}

\section{SCHOLARONE Manuscripts}


Measurement of inbreeding depression in Rhododendron kaempferi: seed production, germination, juvenile survival, and growth

Keigo Takahashi, Takao Itino

Keigo Takahashi Graduate School of Science and Technology, Shinshu University, Matsumoto,

Nagano 390-8621, Japan

Takao Itino Department of Biology, Faculty of Science and Institute of Mountain Science,

Shinshu University, Matsumoto, Nagano 390-8621, Japan

Corresponding author: Keigo Takahashi, k11210102088@gmail.com 


\section{Abstract}

To understand the reproductive ecology of a plant species with both selfing and outcrossing reproductive systems, it is important to know how selfed individuals contribute to the maintenance of a population. Further, examination of the magnitude of inbreeding depression after pollination is essential for accurate measurement of reproductive success. In this study, we investigated the characteristics of viable seeds and seedlings of Rhododendron kaempferi in a region where the bumblebee pollinator Bombus ardens are abundant. In a handpollination experiment, the fruit set from self-pollination was $32 \%$, significantly lower than that from outcross-pollination (81\%). The number of seeds per fruit from self-pollination was one sixth the number from outcross-pollination. However, the number of seeds per fruit was negatively correlated with the weight per seed. In addition, the germination rate was low when the seed weight was light. Although selfed seeds could germinate, $89 \%$ of the seedlings died within a year. The inbreeding depression coefficient 1 year after sowing was very high $(0.89)$. These results indicate that $R$. kaempferi shows extremely strong selection for outcrossing but maintains a slight selfing potential in a natural population in central Japan.

Keywords: bumblebee, germination, inbreeding depression, rhododendron, seed 


\section{Introduction}

Inbreeding depression, defined as the reduction in fitness of progeny derived from inbreeding relative to that of progeny derived from outcrossing, has long been an important topic in the reproductive ecology of plants (Charlesworth and Charlesworth 1987). The cause of inbreeding depression is considered to be homozygosis of deleterious recessive genes (Lande and Schemske 1985; Charlesworth and Willis 2009). One advantage of selfing in seed plants is reproductive assurance, but this advantage is counteracted by inbreeding depression (Barrett and Harder 2017). Although repeated inbreeding removes harmful genes from the population and reduces the magnitude of inbreeding depression (Husband and Schemske 1996), selffertilizing populations may be more vulnerable to environmental change than outcrossing ones because of reduced genetic diversity (dead-end hypothesis; Stebbins 1957).

Some plant species have developed mechanisms to prevent self-pollination, including self-incompatibility (where fertilization by self pollen is prevented because pollen tubes do not grow; Takayama and Isogai 2005), dichogamy (in which pistils and stamens in the same flower ripen at different times; Lloyd and Webb 1986), and herkogamy (spatial separation of stamens and pistils; Webb and Lloyd 1986). These mechanisms, which function as pre-fertilization barriers to selfing, limit seed production by selfing. On the other hand, mechanisms associated with inbreeding depression, such as a lower germination rate, lower juvenile survival, and a decline of the growth fitness of progeny derived from selfing promote the evolution of 
outcrossing. Therefore, to know comprehensive evaluation of the effect of selfing in a plant species, it is necessary to examine the magnitude of inbreeding depression exhibited at different life stages: seed production, germination, and juvenile survival and growth.

Some Rhododendron species are weakly self-compatible or self-incompatible (Ng and Corlett 2000; Kudo et al. 2011). In particular, Rhododendron ferrugineum L. in France has been reported to suffer from strong inbreeding depression such that selfed individuals cannot survive to maturity (Delmas et al. 2014). These Rhododendron species are visited by bees (Bombus and Apis spp.). Bees typically consecutively visit flowers that are spatially close for efficient collection of nectar (Herrera 1987); as a result, bee-pollinated plants such as Rhododendron species that have many flowers per plant are often geitonogamous. These Rhododendron species have apparently adopted an outcrossing reproductive strategy while allowing stigma attachment of self pollen (Ng and Corlett 2000; Kudo et al. 2011; Delmas et al. 2014; Hahn et al. 2017).

In central Japan, Rhododendron kaempferi Planch. is visited by both Bombus ardens Smith and the swallowtail butterfly Papilio maackii Ménétriès (Takahashi and Itino 2017), but this species does not exhibit clear dichogamy or herkogamy. Bumblebees and swallowtail butterflies have different flower-visiting behaviors in a Rhododendron species (Takahashi and Itino 2020); thus, P. maackii, a long-distance pollinator, is expected to carry outcross pollen to the stigma of R. kaempferi, and B. ardens, a sequential flower visitor, is expected to carry both 
outcross and self pollen. So, to evaluate the relative contribution of these two pollinator species, it is important to clarify the magnitude of self-compatibility and inbreeding depression in $R$. kaempferi. Therefore, in this study, we investigated the following four points: (1) the difference in the number of consecutive flower visits between B. ardens and P. maackii, (2) the presence or absence of self-incompatibility in R. kaempferi, (3) the effects of inbreeding depression in R. kaempferi on its germination rate and 1-year survival rate, and (4) the effects of inbreeding depression on the growth of seedlings.

\section{Materials and methods}

\section{Plant material}

Rhododendron kaempferi is a semi-deciduous shrub of family Ericaceae that is distributed throughout Japan, except in Okinawa Prefecture (Yamazaki 1996). It grows in clusters along the edges of mixed forests and is mainly visited by Lepidoptera and Hymenoptera (Takahashi and Itino 2017). Its flowering season is from the middle of April to the end of May. Flower life expectancy is about seven days. The fruit has a hard shell covered by bristles, and it matures from October to November. The seeds are very small, $1.0 \mathrm{~mm}$ long by $0.4 \mathrm{~mm}$ wide (Yamazaki 1996). Mean seed weight is 0.0894 g (average of 1000 seeds; Royal Botanic Gardens Kew 2017). This species propagates via clones grown from rhizomes, in addition to seed propagation (Aizawa et al. 2016). 


\section{Study site}

Flower observations and hand-pollination experiments were performed at Ikeda, Nagano Prefecture $\left(36^{\circ} 23^{\prime} \mathrm{N}, 137^{\circ} 53^{\prime} \mathrm{E}\right.$; 633-646 m a.s.1.), over eight days from 29 April to 14 May 2017. This period included the flowering peak of $R$. kaempferi. The study site was a mixed forest consisting mainly of Chamaecyparis obtusa Sieb. et Zucc., with about 50 R. kaempferi bushes growing within an area of $50 \mathrm{~m} \times 50 \mathrm{~m}$ at the forest edge.

\section{Observation of flower visitors}

We observed flower visitors at the study site for a total of six hours, from 9:00 to 15:00 local time, on 14 May 2017. First, we established a $2 \mathrm{~m} \times 3 \mathrm{~m}$ quadrat at the forest edge as the observed population, and then we counted the number of $R$. kaempferi flowers in the quadrat (414 flowers). We treated insect individuals that inserted their proboscis into the nectar tubes of flowers as flower-visiting individuals. We recorded the species and caste (bumblebees only) of each insect visitor, the number of insects of that species (caste) that visited flowers in the quadrat, and the number of flowers that were visited, during each hour of the observation period. Flower visitation frequency of each species or caste, calculated as the number of visiting insects per flower per hour, was compared between bumblebees and swallowtail butterflies by the Brunner-Munzel test in R version 3.4.0 (R core team 2017). 


\section{Hand-pollination experiment}

To determine the magnitude of self-compatibility in $R$. kaempferi, we carried out an artificial pollination experiment with selfing and outcrossing treatments. Fruit set, number of seeds per fruit, and weight per seed were recorded. For this experiment, 25 R. kaempferi bushes in the survey area $(50 \mathrm{~m} \times 50 \mathrm{~m}$ area of the forest edge) were randomly selected, and two pairs of inflorescences with buds on each shrub were bagged. The first and second inflorescence of each pair were used for self- and outcross-pollination, respectively. One flower per infloresence was used, and flowers not used in the experiments were removed before the selected inflorescences were bagged. After the artificial pollination treatment, the stamens of the pollinated flowers were cut out. Pollen grains used for outcross pollination were collected from individuals at least $10 \mathrm{~m}$ away from the maternal shrub. The resulting fruits were collected from 1 to 25 November and stored indoors for 5-7 days. Seeds were removed after dehiscence of the tips of the fruits. Seeds of each fruit were divided into groups of 100, which were weighed on a microelectronic balance (ER-182A, A and D Co., Tokyo, Japan). In fruits with less than 100 seeds, all seeds were counted and weighed. The weight of individual seeds in each fruit was determined as follows: For fruits with less than 100 seeds, (total weight of seeds) / (total number of seeds); for fruits with 100 or more seeds, (sum of the weights of each group of 100 seeds)/ (the total number of seeds in the measured groups). Fruit set between selfing and outcrossing 
was compared by Fisher's exact test. The number of seeds per fruit and seed weight in selfing and outcrossing treatments were compared by Wilcoxon's rank-sum test. In addition, Pearson's product moment correlation coefficient $r$ and $t$ statistics were calculated to determine whether the number of seeds per fruit was correlated with seed weight. A no-correlation test was performed. We used R version 3.4.0 for all statistical analyses ( $\mathrm{R}$ core team 2017).

\section{Germination and growing experiment}

To examine whether selfed seeds of $R$. kaempferi were less likely to germinate than outcrossed seeds and whether seed weight affected their growth, we recorded the germination rate of seeds from each fruit and the number of days required for the seed leaves to open. First, 56 seeds per fruit (except 36 seeds for the selfed fruit of individual No. 7) were randomly selected. On 19 March 2018, we mixed water and sphagnum moss in a mixer (MX-X42, Matsushita Electric Industrial Co., Ltd., Osaka, Japan). Pasty sphagnum moss was spread on trays of plugs $(1.5 \mathrm{~cm} \times 1.5 \mathrm{~cm} \times 2.5 \mathrm{~cm}$ deep, 406 plugs per tray $)$, and seeds were placed on one per plug. The trays were kept indoors where ventilation was good and out of direct sunlight. The germination rate was assessed on 29 April, and the difference in germination rate between selfed and outcrossed seeds was compared using Fisher's exact test (R core team 2017). A $t$ test was performed to compare the number of days required for the seed leaves to open between the selfing and outcrossing treatments. A regression analysis was conducted to assess whether 
seed weight affected the germination rate or the number of days required for the seeds leaves to open.

To determine whether inbreeding depression affected the early stage of seedling growth, we recorded the numbers of surviving and dead seedlings each day from 30 April 2018 to 20 March 2019. The number of leaves on each surviving individual was counted every 3 months from the sowing date as an index of the growth rate. From 2 to 14 May, newly prepared trays of plugs $(2.0 \mathrm{~cm} \times 2.0 \mathrm{~cm} \times 3.5 \mathrm{~cm}$ deep, 288 plugs per tray $)$ covered with sphagnum moss, and seedlings were replanted into them. Then, from 8 to 16 July, the seedlings were again replanted into prepared nursery boxes covered with acid soil (blueberry soil, PROTOLEAF, Inc., Tokyo, Japan). As in the germination experiment, the seedlings were grown indoors with good ventilation and out of direct sunlight. Temperatures varied between approximately $0^{\circ} \mathrm{C}$ and $35^{\circ} \mathrm{C}$ during the four seasons. Each individual was assessed daily for life and death. Water was supplied as appropriate to the dryness of the soil. Individuals that had not formed seed leaves as of 12 June were treated as dead. Individuals that died by insect damage were excluded from the data set. Survival curves (Kaplan-Meier method with log-rank test) of selfed and outcrossed progenies were drawn by using EZR software (Kanda 2013). The number of leaves between selfed and outcrossed seedlings was compared by $t$-test every 3 months from the sowing date (19 March 2018). Regression analysis was conducted to determine whether seed weight affected the survival rate 1 year after sowing or the number of leaves every 3 months. 
The magnitude of inbreeding depression $(\delta)$ after 1 year was determined as follows

(Lande and Schemske 1985):

$$
\delta=1-\left(W_{\mathrm{s}} / W_{\mathrm{o}}\right)
$$

where $W_{\mathrm{s}}$ and $W_{\mathrm{o}}$ are selfing and outcrossing fitness, respectively. Following Ågren and Schemske (1993), $W$ was estimated as follows:

$$
W=(\text { number of seeds }) \times(\text { germination rate }) \times(1 \text {-year survival rate })
$$

This calculation was carried out using the data of individuals from which both selfed and outcrossed fruits were obtained in the hand-pollination experiment (Individuals 7, 8, 12, 15 , and 23).

\section{Results}

\section{Flower visitation frequency}

In 2017, B. ardens (queens and workers) visited significantly more R. kaempferi flowers than P. maackii (the number of hours of observation $=6$, d.f. $=5.20, p=0.008$; Table 1). In particular, B. ardens workers tended to visit many adjacent flowers in the observed population (Table 1).

Fruit set, number of seeds per fruit, and seed weight in selfing and outcrossing treatments Rhododendron kaempferi showed weak self-compatibility. Fruit set following outcross 
pollination was $81.0 \%(17 / 21)$, which was significantly higher than that of $31.8 \%(7 / 22)$ following self-pollination $(p=0.002)$. The number of seeds per fruit from outcrossing $(471.2 \pm$ 53.4, mean \pm S.E., $n=16)$ was 6 times that from selfing $(79.0 \pm 13.6, n=6)(W=4, p=0.0003)$. The weight per seed did not differ significantly $(W=66, p=0.20)$ between selfing $(0.110 \pm$ $0.011 \mathrm{mg}, n=6$, mean \pm S.E. $)$ and outcrossing $(0.090 \pm 0.006 \mathrm{mg}, n=16)$. Pearson's productmoment correlation $r$ showed that the number of seeds was negatively correlated with seed weight $(r=-0.62, t=3.57$, d.f. $=20, p=0.002$; Fig. 1$)$.

\section{Factors affecting germination rate and seedling survival rate}

Although selfed seeds of $R$. kaempferi germinated normally, most died as a result of inbreeding depression at an early life stage (Table 2). The germination rate of fruits with heavier per seed weights was higher (Table 3), with no significant difference between selfing and outcrossing treatments (selfing, $n=316$; outcrossing, $n=896 ; p=0.57$ ). The 1-year survival rate (number of surviving seedlings / number that germinated) of outcrossed seedlings was significantly greater than that of selfed seedlings $\left(n=829, p=5.26 \times 10^{-16}\right.$; Fig. 2$)$, but no effect of seed weight was observed (Table 3). The survival rate of seedlings, especially selfed seedlings, decreased rapidly from 110 to 140 days after sowing (Fig. 2). This period corresponded to the middle of summer in Japan. The inbreeding depression coefficient $\delta$ was very high at $0.89 \pm 0.03($ mean \pm S.E., $n=5)$. 


\section{Factors affecting seedling growth}

The number of days required for seed leaves to open was not clearly different between selfing (27.7 \pm 0.4 days, mean \pm S.E., $n=213)$ and outcrossing $(27.3 \pm 0.2$ days, $n=624 ; t=$ $0.85, p=0.40$; Table 2) treatments. Seed weight also had no significant effect on the number of days (Table 3). At 3 months after sowing, the number of leaves of selfed seedlings $(3.11 \pm$ 0.04 , mean \pm S.E., $n=209)$ was significantly higher $(t=3.10, p=0.002$; Fig. 3$)$ than that of outcrossed seedlings $(2.98 \pm 0.02, n=611)$. However, at 6 months after sowing, the situation was reversed; the number of leaves of selfed seedlings increased to $4.15 \pm 0.20(n=75)$ but that of outcrossed seedlings increased to $4.80 \pm 0.06(n=371, t=3.90, p=0.0001$; Fig. 3$)$. At 9 months (selfing, $5.47 \pm 0.37$ leaves, $n=30$; outcrossing, $5.77 \pm 0.11$ leaves, $n=266 ; t=0.86$, $p=0.39$ ) and 12 months (selfing, $5.67 \pm 0.49$ leaves, $n=24$; outcrossing, $6.15 \pm 0.15$ leaves, $n$ $=215 ; t=1.05, p=0.30)$, the number of leaves of outcrossed seedlings was slightly higher than that of selfed seedlings but the differences were not statistically significant (Fig. 3). An effect of seed weight on the number of leaves was observed 3 and 6 months after sowing, but not after 9 or 12 months (Table 4$)$.

\section{Discussion}

Queens and workers of B. ardens were the main flower visitors to R. kaempferi at the 
study site (Table 1). Because R. kaempferi individuals have a large number of flowers blooming at the same time, workers of $B$. ardens, which consecutively visit spatially close flowers, are assumed to carry both self and outcross pollen to stigmas (Karron et al. 2009; Table 1). On the other hand, pollination by P. maackii occurred remarkably less often. Papilio maackii does not stay long at one plant individual but moves frequently between shrubs while seeking flower rewards (Takahashi and Itino 2020). In this study, outcross pollination by this species might be more efficient, although the sample size of P. maackii was small.

Similar to other Rhododendron species pollinated by bees (Ng and Corlett 2000), we observed weak self-compatibility in R. kaempferi. The weak self-compatibility of $R$. kaempferi ensures that some seeds will be produced even if the stigmas become covered with self pollen. Also, even slight self-compatibility allows $R$. kaempferi to switch its mating system to autonomous self-pollination when pollinators are absent. For example, in the Izu Islands, where no bumblebees are found, $R$. kaempferi bushes have smaller flowers and reproduce entirely by self-pollination (Inoue 1993).

However, in our study area, selfed $R$. kaempferi seedlings were vulnerable to summer conditions (Fig. 2) and most died within a year (Table 2). Interception of ovules by self pollen should be a considerable waste of reproductive resources when the magnitude of inbreeding depression is strong. Given the presence of insect pollinators in the study area, why is this waste maintained in nature? The answer to this question remains unclear. 
In R. kaempferi, the number of seeds per fruit resulting from outcrossing ranged widely, from 88 to 845 seeds (Table 2). On the whole, the relationship between number of seeds per fruit and seed weight showed a tradeoff, but there was a large difference in this tendency between selfed and outcrossed fruits (Fig. 1). The low number of seeds in selfed fruits may be due to the weak self-compatibility. In Rhododendron species, when self pollen attaches to the stigma, the chance of outcross pollination occurring is reduced (Kudo et al. 2011; Delmas et al. 2014; Takahashi and Itino 2020). In this study, when more than 600 ovules were fertilized simultaneously by outcross pollen, the resulting weight per seed became lighter and the germination rates decreased (Tables 2,3). This phenomenon could be regarded as a failure of seed maturation due to resource limitation (restriction of seed production by the amount of nutrients and photosynthetic products; Lee 1988). In fruits composed of many ovules, a mixture of self and outcross pollen adhering to the stigma presumably result in a reduced number of seeds per fruit and, thus, heavier outcrossed seeds with a greater likelihood of survival. Further investigation is needed to determine whether the resource limitation of $R$. kaempferi depends only on the number of seeds per fruit.

Seed weight had no significant effect on the number of days required for seed leaves to open, but the number of leaves 3 and 6 months after sowing tended to increase as the seed weight increased (Table 4). This result suggests that different mechanisms affect the growth rate before and after seed leaves open. For example, although the number of days required for 
seed leaves to open is determined by external factors such as temperature, seed weight may also have a strong effect on the early growth rate of seedlings.

Changes in the number of leaves did not show a consistent trend between selfing and outcrossing (Fig. 3). However, the individual differences in the number of leaves in selfed seedlings increased more than that in outcrossed seedlings over time (Fig. 3). This is probably because some selfed individuals failed to recover from damage caused by summer conditions.

Inbreeding depression remains a central topic in the studies of the evolution and conservation of organisms (Hedrick and Garcia-Dorado 2016). Ongoing global climate change and dwindling numbers of pollinators have a major impact on plant population survival and mating systems (Eckert et al. 2010). Our study reports extremely strong selection for outcrossing and a slight selfing potential in a natural R. kaempferi population of bumblebeerich region, in central Japan.

\section{Acknowledgements}

We thank the Ikeda Town Hall, Azumino Ikeda Craft Park, and other landowners for permission to work in the study area as well as Susan Duhon for editing this manuscript.

\section{Funding}

This research was supported by the Nagano Society for the Promotion of Science. 


\section{Conflict of interest}

The authors declare that they have no conflict of interest. 


\section{References}

Ågren, J., and Schemske, D.W. 1993. Outcrossing rate and inbreeding depression in two annual monoecious herbs, Begonia hirsuta and B. semiovata. Evolution, 47(1): 125-135. doi.org/10.1111/j.1558-5646.1993.tb01204.x.

Aizawa, M., Nakayama, C., and Ohkubo, T. 2016. Comparison of fine-scale spatial genetic structure of two sympatric Rhododendron shrub species in forest habitat having different seed weights: A case study. Silvae Genet. 65(2): 39-45. doi.org/10.1515/sg-2016-0015.

Barrett, S.C.H., and Harder, L.D. 2017. The ecology of mating and its evolutionary consequences in seed plants. Annu. Rev. Ecol. Evol. Syst. 48: 135-157. doi.org/10.1146/annurev-ecolsys-110316-023021.

Charlesworth, D., and Charlesworth, B. 1987. Inbreeding depression and its evolutionary consequences. Annu. Rev. Ecol. Syst. 18: 237-268. Available from https://www.jstor.org/stable/2097132 [accessed 8 January 2021].

Charlesworth, D., and Willis, J.H. 2009. The genetics of inbreeding depression. Nat. Rev. Genet. 10(11): 783-796. doi.org/10.1038/nrg2664.

Delmas, C.E., Cheptou, P.O., Escaravage, N., and Pornon, A. 2014. High lifetime inbreeding depression counteracts the reproductive assurance benefit of selfing in a mass-flowering shrub. BMC Evol. Biol. 14(1): 243. doi.org/10.1186/s12862-014-0243-7. 
Eckert, C.G., Kalisz, S., Geber, M.A., Sargent, R., Elle, E., Cheptou, P.O., Goodwillie, C., Johnston, M.O., Kelly, J.K., Moeller, D.A., Porcher, E., Ree, R.H., Vallejo-Marín, M., and Winn. A.A. 2010. Plant mating systems in a changing world. Trends Ecol. Evol. 25(1): 35-43. doi.org/10.1016/j.tree.2009.06.013.

Hahn, C.Z., Michalski, S.G., and Durka, W. 2017. Gene flow in, and mating system of, Rhododendron simsii in a nature reserve in subtropical China. Nord. J. Bot. 35(1): 1-7. doi.org/10.1111/njb.01311.

Hedrick, P.W., and Garcia-Dorado, A. 2016. Understanding inbreeding depression, purging, and genetic rescue. Trends Ecol. Evol. 31(12): 940-952. doi.org/10.1016/j.tree.2016.09.005.

Herrera, C.M. 1987. Components of pollinator "quality": comparative analysis of a diverse insect assemblage. Oikos, 50(1): 79-90. doi.org/10.2307/3565403.

Husband, B.C., and Schemske, D.W. 1996. Evolution of the magnitude and timing of inbreeding depression in plants. Evolution, 50(1): 54-70.

doi.org/10.1111/j.1558-5646.1996.tb04472.x.

Inoue, K. 1993. Evolution of mutualism in plant-pollinator interactions on islands. J. Biosci. 18(4): 525-536. doi.org/10.1007/BF02703084.

Kanda, Y. 2013. Investigation of the freely available easy-to-use software 'EZR' for medical statistics. Bone Marrow Transplant. 48(3): 452-458. doi.org/10.1038/bmt.2012.244. 
Karron, J.D., Holmquist, K.G., Flanagan, R.J., and Mitchell, R.J. 2009. Pollinator visitation patterns strongly influence among-flower variation in selfing rate. Ann. Bot. 103(9): 1379-1383. doi.org/10.1093/aob/mcp030.

Kudo, G., Hirao, A.S., and Kawai, Y. 2011. Pollination efficiency of bumblebee queens and workers in the alpine shrub Rhododendron aureum. Int. J. Plant Sci. 172(1): 70-77. doi.org/10.1086/657282.

Lande, R., and Schemske, D.W. 1985. The evolution of self-fertilization and inbreeding depression in plants. I. Genetic models. Evolution, 39(1): 24-40. doi.org/10.1111/j.1558-5646.1985.tb04077.x.

Lee, T. D. 1988. 'Patterns of fruit and seed production' in Doust, J. L. and Doust, L. L. (eds.) Plant reproductive ecology: patterns and strategies, New York: Oxford University Press, pp. 179-202.

Lloyd, D.G., and Webb, C.J. 1986. The avoidance of interference between the presentation of pollen and stigmas in angiosperms I. Dichogamy. N. Z. J. Bot. 24(1): 135-162. doi.org/10.1080/0028825X.1986.10409725.

Ng, S.C., and Corlett, R.T. 2000. Comparative reproductive biology of the six species of Rhododendron (Ericaceae) in Hong Kong, South China. Can. J. Bot. 78(2): 221-229. doi.org/10.1139/b99-181. 
R Core Team. 2017. R: A language and environment for statistical computing. R Foundation for Statistical Computing, Vienna, Austria. Available from https:/www.R-project.org/ Royal Botanic Gardens Kew. 2017. Seed information database. Available at http://data.kew.org/sid/ [accessed 28 November 2017].

Stebbins, G.L. 1957. Self fertilization and population variability in the higher plants. Am. Nat. 91(861): 337-354.

Takahashi, K., and Itino, T. 2017. Visitation frequencies of bumblebees and swallowtail butterflies to flowers and the nectar sugar concentration of Rhododendron kaempferi and R. japonicum in mountains of central Japan. J. Pollinat. Ecol. 21(5): 92-97. doi.org/10.26786/1920-7603(2017)438.

Takahashi, K., and Itino, T. 2020. Comparison of flower-visiting behaviour of bumblebees and swallowtail butterflies to the Japanese azalea (Rhododendron japonicum). J. Pollinat. Ecol. 26(4): 32-37. doi.org/10.26786/1920-7603(2020)595.

Takayama, S., and Isogai, A. 2005. Self-incompatibility in plants. Annu. Rev. Plant Biol. 56(1): 467-489. doi.org/10.1146/annurev.arplant.56.032604.144249.

Webb, C.J., and Lloyd, D.G. 1986. The avoidance of interference between the presentation of pollen and stigmas in angiosperms II. Herkogamy. N. Z. J. Bot. 24(1): 163-178. doi.org/10.1080/0028825X.1986.10409726. 
Yamazaki, T. 1996. A revision of the genus Rhododendron in Japan, Taiwan, Korea and

Sakhalin. Tsumura Laboratory, Tokyo, Japan. 
Table 1. Flower visitation frequency by Bombus ardens and Papilio maackii to

Rhododendron kaempferi. Visitation frequencies are shown per flower per hour (mean \pm

S.E.). Number of insects is the number of each insect species or caste that visited the observed population during the 6-h observation. Number of flower visits represents the number of flowers in the observed population that each insect visited consecutively.

\begin{tabular}{llccl}
\hline Insect name & Caste & $\begin{array}{l}\text { Number of } \\
\text { insects }\end{array}$ & $\begin{array}{l}\text { Number of } \\
\text { flower visits }\end{array}$ & $\begin{array}{l}\text { Visitation } \\
\text { frequency }\end{array}$ \\
\hline \multirow{2}{*}{ Bombus ardens } & Queen & 3 & $6.7 \pm 2.9$ & $0.0081 \pm 0.0071$ \\
& Worker & 9 & $16.1 \pm 6.9$ & $0.0584 \pm 0.0521$ \\
Papilio maackii & - & 1 & 2.0 & $0.0008 \pm 0.0008$ \\
\hline
\end{tabular}


Table 2. Germination rate, number of days required for seed leaves to open, and survival rate of seedlings of Rhododendron kaempferi. The germination rate was calculated as (number of germinated seeds) / (number of sown seeds), and the survival rate of seedlings as (number of surviving seedlings) / (number of germinated seeds). The number of days required for the seed leaves to open are indicated as mean \pm S.E.

\begin{tabular}{|c|c|c|c|c|c|c|c|c|c|c|c|}
\hline \multirow{3}{*}{$\begin{array}{l}\text { Individual } \\
\text { No. } \\
\text { S-7 }\end{array}$} & \multirow{3}{*}{$\begin{array}{l}\text { Number of } \\
\text { seeds } \\
38\end{array}$} & \multirow{3}{*}{$\begin{array}{l}\text { Seed weight* } \\
(\mathrm{mg}) \\
0.0921\end{array}$} & \multirow{2}{*}{\multicolumn{2}{|c|}{ Germination rate }} & \multirow{2}{*}{\multicolumn{2}{|c|}{$\begin{array}{l}\text { Number of days required } \\
\text { for seed leaves to open }\end{array}$}} & \multicolumn{4}{|c|}{ Survival rate of seedlings } & \multirow{3}{*}{$\begin{array}{l}\text { Estimated number of } \\
\text { surviving individuals } \\
3.2\end{array}$} \\
\hline & & & & & & & \multicolumn{2}{|c|}{6 months } & \multicolumn{2}{|c|}{1 year } & \\
\hline & & & 0.306 & $(11 / 36)$ & $32.8 \pm 0.8$ & $(10)$ & 0.545 & $(6 / 11)$ & 0.273 & $(3 / 11)$ & \\
\hline S-8 & 63 & 0.1175 & 0.768 & $(43 / 56)$ & $31.5 \pm 1.0$ & (43) & 0.524 & $(22 / 42)$ & 0.214 & $(9 / 42)$ & 10.4 \\
\hline S-12 & 94 & 0.1106 & 0.714 & $(40 / 56)$ & $26.3 \pm 0.8$ & (39) & 0.250 & $(10 / 40)$ & 0.000 & $(0 / 40)$ & 0.0 \\
\hline S-15 & 68 & 0.0735 & 0.839 & $(47 / 56)$ & $25.7 \pm 0.5$ & (47) & 0.319 & $(15 / 47)$ & 0.043 & $(2 / 47)$ & 2.4 \\
\hline S-21 & 75 & 0.1107 & 0.536 & $(30 / 56)$ & $26.1 \pm 0.9$ & $(30)$ & 0.200 & $(6 / 30)$ & 0.067 & $(2 / 30)$ & 2.7 \\
\hline S-23 & 136 & 0.1570 & 0.786 & $(44 / 56)$ & $27.2 \pm 0.7$ & $(44)$ & 0.364 & $(16 / 44)$ & 0.182 & $(8 / 44)$ & 19.4 \\
\hline Self Total & 474 & - & 0.680 & $(215 / 316)$ & $27.7 \pm 0.4$ & $(213)$ & 0.350 & $(75 / 214)$ & 0.112 & $(24 / 214)$ & 38.1 \\
\hline O-1 & 576 & 0.0666 & 0.625 & $(35 / 56)$ & $32.6 \pm 1.1$ & $(35)$ & 0.600 & $(21 / 35)$ & 0.286 & $(10 / 35)$ & 102.9 \\
\hline $\mathrm{O}-2$ & 88 & 0.1375 & 0.714 & $(40 / 56)$ & $29.6 \pm 0.8$ & $(40)$ & 0.359 & $(14 / 39)$ & 0.051 & $(2 / 39)$ & 3.2 \\
\hline O-5 & 812 & 0.0666 & 0.500 & $(28 / 56)$ & $29.0 \pm 1.1$ & (28) & 0.357 & $(10 / 28)$ & 0.071 & $(2 / 28)$ & 29.0 \\
\hline O-7 & 466 & 0.0793 & 0.589 & $(33 / 56)$ & $26.0 \pm 0.8$ & (33) & 0.545 & $(18 / 33)$ & 0.061 & $(2 / 33)$ & 16.6 \\
\hline O-8 & 576 & 0.0686 & 0.661 & $(37 / 56)$ & $29.5 \pm 0.8$ & $(37)$ & 0.571 & $(20 / 35)$ & 0.229 & $(8 / 35)$ & 87.0 \\
\hline O-9 & 391 & 0.0840 & 0.911 & $(51 / 56)$ & $25.3 \pm 0.6$ & $(51)$ & 0.700 & $(35 / 50)$ & 0.440 & $(22 / 50)$ & 156.7 \\
\hline O-10 & 845 & 0.0785 & 0.339 & $(19 / 56)$ & $28.8 \pm 1.4$ & (19) & 0.579 & $(11 / 19)$ & 0.316 & $(6 / 19)$ & 90.5 \\
\hline O-11 & 363 & 0.0943 & 0.964 & $(54 / 56)$ & $24.7 \pm 0.6$ & $(54)$ & 0.788 & $(41 / 52)$ & 0.577 & $(30 / 52)$ & 201.9 \\
\hline
\end{tabular}




\begin{tabular}{|c|c|c|c|c|c|c|c|c|c|c|c|}
\hline O-12 & 582 & 0.1012 & 0.857 & $(48 / 56)$ & $27.3 \pm 0.9$ & $(48)$ & 0.896 & $(43 / 48)$ & 0.688 & $(33 / 48)$ & 343.0 \\
\hline $\mathrm{O}-13$ & 503 & 0.0948 & 0.911 & $(51 / 56)$ & $24.1 \pm 0.6$ & $(51)$ & 0.725 & $(37 / 51)$ & 0.431 & $(22 / 51)$ & 197.6 \\
\hline O-14 & 430 & 0.1240 & 1.000 & $(56 / 56)$ & $25.1 \pm 0.3$ & $(56)$ & 0.519 & $(28 / 54)$ & 0.352 & $(19 / 54)$ & 151.3 \\
\hline O-15 & 91 & 0.1176 & 0.929 & $(52 / 56)$ & $27.8 \pm 0.8$ & $(51)$ & 0.580 & $(29 / 50)$ & 0.360 & $(18 / 50)$ & 30.4 \\
\hline O-16 & 446 & 0.0893 & 0.196 & $(11 / 56)$ & $35.0 \pm 2.2$ & (11) & 0.545 & $(6 / 11)$ & 0.455 & $(5 / 11)$ & 39.8 \\
\hline O-17 & 314 & 0.0903 & 0.929 & $(52 / 56)$ & $27.3 \pm 0.8$ & $(52)$ & 0.596 & $(31 / 52)$ & 0.333 & $(17 / 51)$ & 97.2 \\
\hline $\mathrm{O}-20$ & 685 & 0.0395 & 0.161 & $(9 / 56)$ & $37.8 \pm 2.2$ & $(8)$ & 0.444 & $(4 / 9)$ & 0.222 & $(2 / 9)$ & 24.5 \\
\hline $\mathrm{O}-23$ & 371 & 0.1150 & 0.893 & $(50 / 56)$ & $26.0 \pm 0.5$ & $(50)$ & 0.460 & $(23 / 50)$ & 0.340 & $(17 / 50)$ & 112.6 \\
\hline $\begin{array}{l}\text { Outcross } \\
\text { Total }\end{array}$ & 7539 & - & 0.699 & $(626 / 896)$ & $27.3 \pm 0.2$ & $(624)$ & 0.602 & $(371 / 616)$ & 0.350 & $(215 / 615)$ & 1684.3 \\
\hline
\end{tabular}

*: Mean per seed value: For fruits with less than 100 seeds = (total weight of seeds) / (total number of seeds); for fruits with 100 or more seeds: (sum of the weights of 100 seed groups) / (total number of seeds measured).

$\uparrow$ : Number of seedlings that would survive for 1 year if all seeds from the fruit had been sown (same as the fitness $W$ in the Materials and methods section). 
Table 3. Results of regression analysis to assess the effects of seed weight on germination rate,

1-year survivorship, and the number of days required for seed leaves to open.

\begin{tabular}{lrrrrc} 
& d.f. & SS & MS & $F$ & $P$ \\
& & & & & \\
& & & & & \\
Germination rate & & 0.31 & 0.31 & 5.86 & $0.03 *$ \\
Seed weight & 20 & 1.05 & 0.05 & & \\
Error & 21 & 1.36 & & & \\
Total & & & & & \\
& & & & \\
Survivorship & 1 & 0.0003 & 0.0003 & 0.01 & 0.92 n.s. \\
Seed weight & 20 & 0.70 & 0.03 & & \\
Error & 21 & 0.70 & & \\
Total & \multicolumn{5}{l}{$\begin{array}{l} \\
\text { Number of days required for seed leaves to open }\end{array}$} \\
Seed weight & 1 & 42.03 & 42.03 & 3.74 & 0.07 n.s. \\
Error & 20 & 225.06 & 11.25 & \\
Total & 21 & 267.09 & & \\
\hline
\end{tabular}

*: $P<0.05$; n.s.: not significant 
Table 4. Results of the regression analysis to assess the effect of seed weight on the number of leaves observed every 3 months.

\begin{tabular}{|c|c|c|c|c|c|}
\hline & d.f. & SS & MS & $F$ & $P$ \\
\hline \multicolumn{6}{|l|}{3 months } \\
\hline Seed weight & 1 & 2.00 & 2.00 & 28.44 & $0.00003 * * *$ \\
\hline Error & 20 & 1.41 & 0.07 & & \\
\hline Total & 21 & 3.41 & & & \\
\hline \multicolumn{6}{|l|}{6 months } \\
\hline Seed weight & 1 & 1.34 & 1.34 & 4.66 & $0.04 *$ \\
\hline Error & 20 & 5.75 & 0.29 & & \\
\hline Total & 21 & 7.08 & & & \\
\hline \multicolumn{6}{|l|}{9 months } \\
\hline Seed weight & 1 & 2.83 & 2.83 & 3.82 & 0.07 n.s. \\
\hline Error & 19 & 14.06 & 0.74 & & \\
\hline Total & 20 & 16.89 & & & \\
\hline \multicolumn{6}{|l|}{12 months } \\
\hline Seed weight & 1 & 2.13 & 2.13 & 1.13 & 0.30 n.s. \\
\hline Error & 19 & 35.88 & 1.89 & & \\
\hline Total & 20 & 38.01 & & & \\
\hline
\end{tabular}

*: $P<0.05 ; * * *: P<0.0001$; n.s.: not significant 


\section{Figure legends}

Fig. 1. Scatter plot between number of seeds and seed weight in selfing $(\circ)$ and outcrossing $(\bullet)$ treatments. Pearson's product-moment correlation $r$ for all data points is $-0.62(P<0.01)$.

Fig. 2. Survival curves seedlings resulting from selfing and outcrossing treatments. Survivorship and the number of days after 30 April 2018 are shown on the vertical and horizontal axes, respectively. The observation end date was 20 March 2019.

Fig. 3. Changes in the number of leaves on young seedlings. The number of leaves and the number of elapsed months from the date of sowing are shown on the vertical and horizontal axes, respectively. The vertical bars show the average number of leaves on selfed and outcrossed seedlings. The error bars show the standard error.

**: $P=0.002 ; * * *: P=0.0001 ;$ n.s.: not significant 


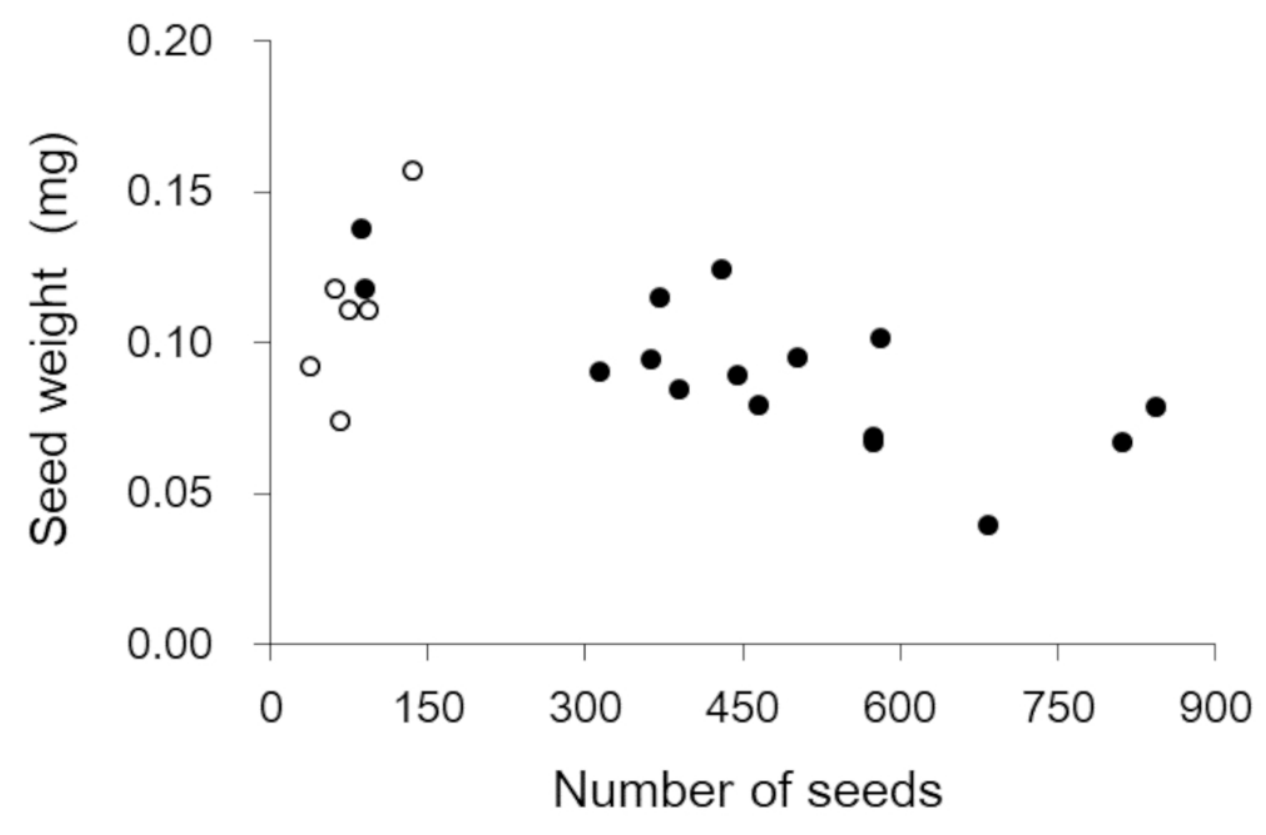

$88 \times 57 \mathrm{~mm}(300 \times 300 \mathrm{DPI})$ 


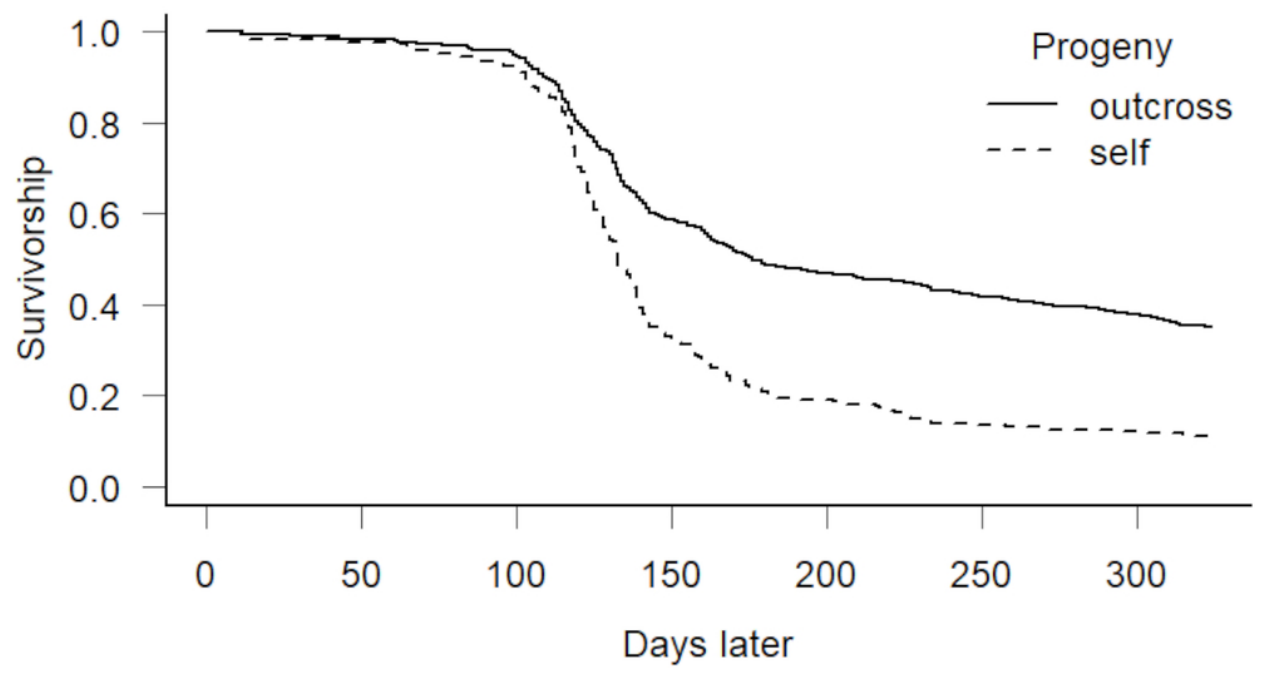

$87 \times 54 \mathrm{~mm}(300 \times 300$ DPI $)$ 


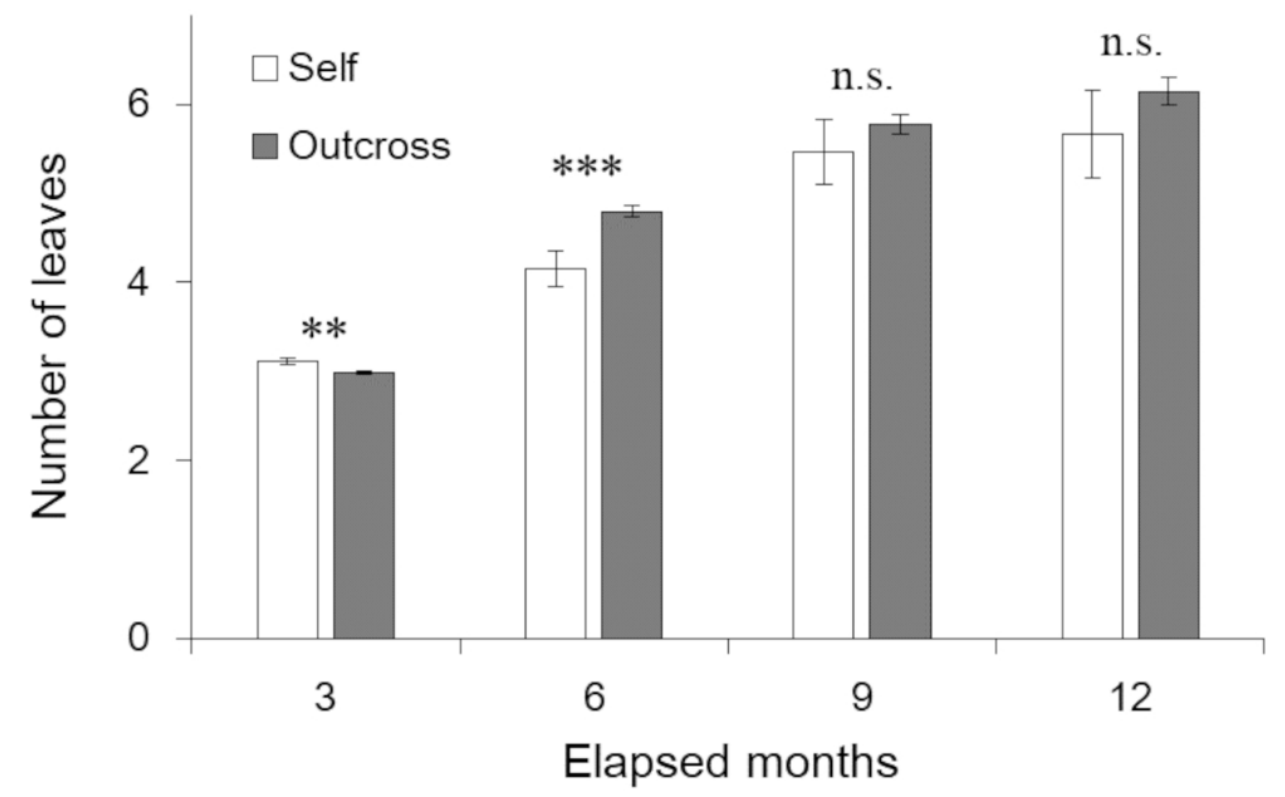

$87 \times 53 \mathrm{~mm}(300 \times 300$ DPI $)$ 